\title{
Involução do financiamento da saúde: explorando dados geográficos regionais
}

Recebido: 28 jan 2019 Aceito: 10 fev 2019

Autor de correspondência: tcuide@yahoo.com.br

Conflito de interesses: Os autores declaram não haver nenhum interesse profissional ou pessoal que possa gerar conflito de interesses em relação a este manuscrito.
(1)Universidade Estadual de Feira de Santana - UEFS, Feira de Santana, BA, Brasil.

\section{Resumo}

Nos países mais ricos, com poucas exceções, a maior parte do financiamento da saúde provém de fontes públicas, sendo que a maior parte do gasto privado é realizada sob a forma de pré-pagamento (planos e seguros privados). O desembolso direto, forma mais iníqua e excludente de financiamento, é, paradoxalmente, maior nos países mais pobres. No Brasil, desde a Constituição de 1988, seguida das Leis 8.080/90 e 8.142/90, os municípios vêm assumindo progressivamente responsabilidades da gestão do Sistema Único de Saúde - SUS em um processo de descentralização crescente. A Emenda Constitucional 29 (EC 29) assegurou a participação das três esferas de governo no financiamento das ações e serviços públicos de saúde, a partir da definição de um aporte anual mínimo de recursos, ficando obrigados, estados e municípios a aplicar $12 \%$ e $15 \%$ da receita de impostos e transferências constitucionais e legais, respectivamente. A alocação e a disponibilidade dos recursos financeiros destinados à saúde são, certamente, fatores importantes para a operacionalização de um sistema municipal de saúde nos moldes universais como o SUS. Desse modo, conhecer as peculiaridades do financiamento da saúde municipal é um passo importante para que se possa governá-lo com mais eficiência. Por outro lado, o financiamento público da saúde é diretamente afetado por decisões políticas, macroeconômicas, pelo contexto de inserção internacional do país, pelos arranjos institucionais e pelas decisões sobre o modelo de proteção social brasileiro. O subfinanciamento é um dos pontos mais frágeis do sistema público de saúde. Isso se deve ao fato do Brasil não gastar o mínimo suficiente e por haver uma tendência de crescimento das necessidades de recursos devido ao crescimento demográfico e a incorporação de novas tecnologias ao processo de diagnóstico e tratamento. Tendo em vista a relevância do tema para o entendimento de como o financiamento do SUS, de fato, é realizado e o cenário de subfinanciamento em que o SUS está inserido, este estudo objetivou identificar as principais fontes de recursos para os municípios da macrorregião Leste do estado da Bahia e analisar os gastos públicos desses municípios com o SUS entre os anos de 2009 e 2015 . Como se trata de um estudo diacrônico, manteve-se na metodologia o formato do Plano Diretor de Saúde - PDR, de 2007. Esta macrorregião englobava, no 
período em estudo, 48 municípios, sendo um destes a capital do estado, Salvador. O objeto da pesquisa foram as receitas federais, estaduais e municipais de saúde recebidas pelos municípios a cada ano do estudo. Para conhecer a origem e direção (uso) das receitas foi utilizado o modelo das Contas Nacionais de Saúde - CNS) / National Health Accounts - NHA que permite a síntese, descrição e análise das informações financeiras utilizando uma matriz com quatro categorias básicas da atenção à saúde: (1) Fontes de Financiamento: responsáveis por fornecer as verbas para o setor da saúde, tais como os recursos de arrecadação tributária federal, estadual e municipal; (2) Agentes de Financiamento: receptores intermediários das verbas de fontes de financiamento e as usam para pagar serviços de saúde e produtos (medicamentos, remédios etc.); (3) Provedores: receptores finais das verbas de cuidados com a saúde. Distribuem os serviços de saúde para a população, ou seja, os hospitais, as clínicas e os postos de saúde; (4) Atividades: ações e serviços que os provedores oferecem com seus recursos, por exemplo, curativos, cuidados de enfermagem, insumos médicos, dentre outros. Estas categorias orientam a montagem das tabelas e a análise. O registro detalhada do fluxo de recursos permite saber quem gasta em saúde, como e quanto. A partir deste modelo foi montada a Tabela 1 (Fontes X Agentes de Financiamento). Os valores relativos às Fontes são as Receitas declaradas pelos municípios ao Sistema de Informações sobre Orçamentos Públicos de Saúde - SIOPS, o Departamento de Informática do SUS DATASUS e o sistema de informação mantido pelo Fundo Nacional de Saúde FNS, todos disponíveis na internet. Uma vez montada a Tabela 1 para cada município da macrorregião estudada, ano a ano, foi realizado o deflacionamento dos valores para melhor comparação entre os anos estudados, tomando como base o Índice Nacional de Preços ao Consumidor Amplo Especial - IPCA. Os resultados apontaram que um volume real total de $R \$ 9,167$ bilhões, quando se controla o efeito da inflação no período. Em termos nominais, o valor total das receitas da macrorregião estudada foi de $R \$ 11,411$ bilhões. Durante o período de 2009 a 2014 constatou-se um acréscimo na receita total de aproximadamente 47,26\%, mas com redução de 2,5\% no fim do período (de 2014 para 2015). Analisando as receitas por habitante percebeu-se que as médias evoluíram no período da seguinte forma: 734,97; 733,06; 785,54; 781,01; 725,91; 748,48; 688,24 e 742,46. A variação ano a ano foi positiva na maioria dos municípios (36 contra 12). As reduções mais acentuadas na receita per capita foram encontradas nos municípios de: Vera Cruz, com uma redução de 89,30\%; Dias D'Ávila, com uma redução de 61,58\%; e São Sebastião do Passé, com uma redução de $42,50 \%$. Por outro lado, alguns municípios apresentaram um acentuado aumento na receita per capita. Destes, destacam-se Muritiba, com 62,60\% de aumento; Saubara, com $43,85 \%$ e Itaparica, com $40,37 \%$ de aumento na receita per capita. De uma maneira geral, quando se observa a macrorregião como um todo, a receita por habitante mostrou uma redução média de 7,16\%, no período estudado. Observou-se uma concentração geográfica de receita, ao se comparar a distância entre os municípios e a capital, sendo que os municípios mais próximos da capital 
apresentavam proporcionalmente receita maior do que aqueles mais distantes. Embora a média percentual de recursos próprios aplicados em saúde tenha sido alta (19,14\%), 16 municípios tiveram variação negativa no período. Do ponto de vista da oferta de serviços, observou-se na macrorregião uma piora em importantes indicadores de saúde como a redução de $20 \%$ no número de famílias acompanhadas na atenção básica e de $4,14 \%$ no número de leitos de internação. Os resultados do estudo que mostram grande variabilidade regional corroboram com os achados em outras regiões e estados, como no Mato Grosso. O levantamento de evidências empíricas para o financiamento poderá superar as lacunas dos estudos de maior magnitude ainda focados em grandes agregados com pouca aplicabilidade na gestão.

Descritores: Financiamento Governamental; Iniquidade Social; Saúde Pública. 